INVITED REVIEW

\title{
SEVERE CONGENITAL NEUTROPENIA TERMINATING IN ACUTE MYELOID LEUKEMIA: DISEASE PROGRESSION ASSOCIATED WITH MUTATIONS IN THE GRANULOCYTE-COLONY STIMULATING FACTOR RECEPTOR GENE
}

\author{
Ivo P. Touw and Fan Dong \\ Department of Hematology, Daniel den Hoed Cancer Center, and Institute of Hematology, Erasmus \\ University, Rotterdam, The Netherlands
}

(Received 22 January 1996. Accepted 23 January 1996)

\begin{abstract}
Severe congenital neutropenia ( $\mathrm{SCN}$ ) is a heterogeneous disease condition with a variable family history and a propensity to progress towards myelodysplastic syndrome (MDS) and acute myeloblastic leukemia (AML). In a subgroup of patients, point mutations in the $G-C S F-R$ gene have been found. These nonsense mutations result in the truncation of the C-terminal cytoplasmic region, a subdomain that is crucial for G-CSF induced maturation. $S C N$ patients with mutations in the G-CSF-R gene appear to be predisposed to develop AML. Here, we recapitulate our view of how defective G-CSF-R may contribute to neutropenia and leukemogenesis. Copyright (C) 1996 Elsevier Science Ltd.
\end{abstract}

Key words: Severe congenital neutropenia, G-CSF-R defects, progression to acute myeloblastic leukemia.

Severe congenital neutropenia ( $\mathrm{SCN}$ ) is a hematopoietic disorder characterized by profound absolute neutropenia and a maturation arrest of myeloid progenitor cells at the promyelocyte-myelocyte stage. As a result, patients suffer from life-threatening opportunistic infections. The diagnosis SCN is usually made early in infancy. SCN was originally described in 1956 by Kostmann [1] as an autosomal recessive disorder in several Swedish families. Subsequently, a number of other reports have appeared in which a family history of SCN was not apparent [2]. Marrow cells from SCN patients often display a reduced responsiveness to granulocyte-colony stimulating factor (G-CSF) in vitro, but neutrophilic colony formation can usually be induced with elevated G-CSF concentrations. As a result of the severe neutropenia, serum G-CSF levels are often high in SCN patients [3]. Nonetheless, administration of pharmacological dosages of G-CSF in many cases restores granulopoiesis in vivo, thereby reducing the frequency of serious infections and improving the quality of life

Correspondence to: I. P. Touw, Institute of Hematology, Erasmus University (Room H Ee 1314), P.O. Box 1738, 3000 DR Rotterdam, The Netherlands (Tel: 3110 4087837; Fax: 31 10 4362315).
$[4,5]$. Only rarely, GM-CSF treatment is effective in these patients $[4,6]$. A major concern is that SCN patients have an increased probability of developing MDS or AML [5, 7-9].

G-CSF binds to a membrane receptor (G-CSF-R) that belongs to the now well-known superfamily of hematopoietin/cytokine receptors [10]. G-CSF binding results in the formation of homodimeric G-CSF-R complexes, which is essential for activation of the receptors. Because defective G-CSF production and release of inhibitors of G-CSF activity could be excluded as the possible mechanisms causing neutropenia in SCN [11], it had been anticipated for some time that G-CSF-R dysfunction might be involved in the pathogenesis of the disease $[3,4]$. This idea gained support when a somatic mutation in the $G-C S F-R$ gene was found in a case of $S C N$ [12]. This nonsense mutation resulted in the deletion of the C-terminal domain of G-CSF-R that has been functionally linked to maturation signaling $[13,14]$. Indeed, upon its ectopic expression in murine myeloid cell lines, the mutant receptor protein failed to induce neutrophilic maturation. Because the normal $G$ $C S F-R$ allele was also expressed in the myeloid cells of the patient, it was important to investigate whether the truncated receptor protein functioned in a dominant 
negative manner over the wild-type protein. Co-transfection experiments, in which truncated and wild-type G-CSF-R proteins were expressed at equal levels in murine myeloid 32D cells, showed that this was indeed the case [15]. The dominant negative model also provides an explanation for the beneficial effects of GCSF therapy in this patient, if one assumes that only at pharmacological concentrations of G-CSF sufficient wild type G-CSF-R homodimers capable of maturation signaling will be formed. Importantly, the mutation was found in the granulocytes of the patient (who received G-CSF treatment), but not in monocytes, erythroid colony cells, $\mathrm{T}$ and $\mathrm{B}$ lymphocytes and skin fibroblasts. Apparently, progenitor cells committed to the granulocyte lineage had been the target population for the somatic mutation. Because normal committed progenitor cells are considered incapable of indefinite multiplication, the question arose as to how the affected progenitor cell population could persist in the patient. Given the fact that the truncated G-CSF-R protein, apart from lacking maturation signaling abilities, also misses the C-terminal element that negatively regulates proliferation, it was suggested that expression of this mutant receptor contributed to immortalization/enhanced selfrenewal capacity of the myeloid progenitor cells. On this basis, the neutropenia in this case was believed to reflect a pre-leukemic condition. In support of this notion, it was shown that the leukemic cells from two AML patients with a history of SCN also had mutations in $G$ $C S F-R$, again truncating the C-terminal maturationinducing region [15]. In one of these patients, it could be demonstrated that the mutation was already present in the neutropenic phase of the disease. Until now, mutations in the $G-C S F-R$, all resulting in the truncation of the C-terminal maturation domain, have been found in five cases (Dong et al., manuscript in preparation). At the time of writing, four of these patients have developed AML.

Mechanisms other than $G-C S F-R$ mutations have also been associated with leukemic transformation in patients with congenital neutropenia. Recently, Kalra et al. [16] reported 13 cases with leukemic transformation. Ten of these showed monosomy 7 . Five patients had activating RAS mutations, four of whom also had monosomy 7. In contrast to the $G-C S F-R$ mutations, monosomy 7 and RAS mutations were detected at the stage of leukemic transformation, but not during the neutropenic phase of the disease, suggesting that these abnormalities are associated with disease progression and not with disease onset.

What is the frequency of $G-C S F-R$ mutations in SCN? This question cannot definitely be answered yct. In our series completed to date, the frequency is 5 out of 25 , i.e. $20 \%$. However, this series cannot be considered as a randomly selected cohort of patients, because patients with disease progression towards AML were deliberately included. In two other studies comprising four and eight cases of SCN, respectively, no $G-C S F-R$ mutations were detected $[17,18]$. Taken together, the data indicate that the frequency of $G$-CSF-R mutations in SCN will be in the order of $10 \%$, or less. This would suggest that, in the majority of patients, signaling molecules downstream of G-CSF-R are affected. Rauprich et al. [19] showed that the ability of G-CSF to activate the JAK2 kinase, which is mediated via the membrane proximal cytoplasmic region of G-CSF-R [20], is not lost in the granulocytic cells of SCN patients. In view of our findings in SCN with $G-C S F-R$ mutations, we think that it is more likely that other disease mechanisms will involve signaling molecules linked to the membrane distal cytoplasmic region of G-CSF-R, i.e. the domain associated with maturation signaling $[13,14]$.

A final question that arises is whether mutations in the $G-C S F-R$ are restricted to cases of SCN or AML with a history of SCN. In 25 cases of de novo AML that we have studied thus far, nonsense mutations in the $G-C S F$ $R$ truncating the $\mathrm{C}$-terminal maturation domain, have not been detected. However, a different type of $G-C S F-R$ mutation was found in the leukemic blasts of one patient with de novo AML [20]. This mutation was discovered after performing reverse transcriptase-polymerase chain reaction (RT-PCR) analysis on the blast cells of 40 nonselected patients. The AML blasts of this patient showed high expression of a new mRNA splice variant, in which the carboxy-terminus was altered due to a change in the reading frame. Analysis of cDNA and corresponding genomic sequences revealed a $G$ to $A$ transition next to a (cryptic) splice donor site involved in the altcrnative RNA splicing. The splice variant was unable to transduce proliferation and maturation signals upon transfer to murine cell systems [20]. In agreement with this, the primary AML blast cells of the patient failed to respond to G-CSF in proliferation assays, whereas the responsiveness to IL-3 or GM-CSF was maintained. This observation, although as yet anecdotal, suggests that G-CSF-R dysfunction, either caused by structural defects in the G-CSF-R itself, or by abnormalities in the maturation signaling function, may also play a role in de novo AML.

Acknowledgement-This work was supported by The Dutch Cancer Society 'Koningin Wilhelmina Fonds'.

\section{References}

1. Kostmann R. (1956) Infantile genetic agranulocytosis. Acta Paediatr. Scand. 45, (Suppl. 105), 1.

2. Dale D. C., Davis M. \& Vincent M. E. (1994) Use of filgrastim (r-metHuG-CSF) in severe chronic neutropenia. In Filgrastin in Clinical Practice (Morstyn G. \& Dexter T. M., Eds), pp. 83-101. Marcel Dekker, New York. 
3. Mempel K., Pietsch T., Menzel T., Zeidler C. \& Welte K. (1991) Increased serum levels of granulocyte colonystimulating factor in patients with severe congenital neutropenia. Blood 77, 1919.

4. Gillio A. P. \& Gabrilove J. L. (1993) Cytokine treatment of inherited bone marrow failure syndromes. Blood 81, 1669.

5. Bonilla M. A., Dale D., Zeidler C., Last L., Reiter A., Ruggeiro M., Davis M., Koci B., Hammond W., Gillio A. \& Welte K. (1994) Long-term safety of treatment with recombinant human granulocyte colony-stimulating factor (r-metHuG-CSF) in patients with severe congenital neutropenias. Br. J. Haematol. 88, 723.

6. Welte K., Zeidler C., Reiter A., Müller W., Odenwald E., Souza L. \& Riehm H. (1990) Differential effects of granulocyte-macrophage colony-stimulating factor and granulocyte colony-stimulating factor in children with severe congenital neutropenia. Blood 75, 1056.

7. Gilman P. A., Jackson D. P. \& Guild H. G. (1970) Congenital agranulocytosis: prolonged survival and terminal acute leukemia. Blood 36, 576.

8. Rosen R. B. \& Kang S. J. (1979) Congenital agranulocytosis terminating in acute myelomonocytic leukemia. $J$. Pediatr. 94, 406.

9. Wong W.-Y., Williams D., Slovak M. L., Charak B., Mazumder A., Snyder D., Powars D. R. \& Brynes R. K. (1993) Terminal acute myelogenous leukemia in a patient with congenital agranulocytosis. Am. J. Hematol. 43, 133.

10. Bazan J. F. (1990) Structural design and molecular evolution of a cytokine receptor superfamily. Proc. natn. Acad. Sci. USA 87, 6934.

11. Pietsch T., Bührer C., Mempel K., Menzel T., Steffens U., Schrader C., Santos F., Zeidler C. \& Welte K. (1991) Blond mononuclear cells from patients with severe congenital neutropenia are capable of producing granulocyte colony-stimulating factor. Blood 77, 1234.

12. Dong F., Hoefslout L. H., Schelen A. M., Broeders L. C. A. M., Meijer Y., Veerman A. J. P., Touw I. P. \& Löwenberg B. (1994) Identification of a nonsense mutation in the granulocyte-colony-stimulating factor receptor in severe congenital neutropenia. Proc. natn. Acad. Sci. USA 91,4480 .
13. Dong F., Van Buitenen C., Pouwels K., Hoefsloot L. H., Löwenberg B. \& Touw I. P. (1993) Distinct cytoplasmic regions of the granulocyte colony-stimulating factor receptor involved in induction of proliferation and maturation. Mol. Cell. Biol. 13, 7774.

14. Fukunaga R., Ishizaka-Ikeda E. \& Nagata S. (1993) Growth and differentiation signals mediated by different regions in the cytoplasmic domain of granulocyte colony stimulating factor receptor. Cell 74, 1079.

15. Dong F., Brynes R. K., Tidow N., Welte K., Löwenberg B. \& Touw I. P. (1995) Mutations truncating the C-terminal maturation region of the G-CSF receptor in acute myeloid leukemia preceded by severe congenital neutropenia. $N$. Engl. J. Med. 333, 487.

16. Kalra R., Dale D., Freedman M., Bonilla M. A., Weinblatt M., Ganser A., Bowman P., Abish S., Priest J., Oseas R. S., Olson K., Paderanga D. \& Shannon K. (1995) Monosomy and activating RAS mutations accompany malignant transformation in patients with congenital neutropenia. Blood 86, 4579.

17. Guba S. C., Sartor C. A., Hutchinson R., Boxer L. A. \& Emerson S. G. (1994) Granulocyte colony-stimulating factor (G-CSF) production and G-CSF receptor structure in patients with congenital neutropenia. Blood 83, 1486.

18. Sandoval C., Parganas E., Wang W. \& Ihle J. N. (1995) Lack of alterations in the cytoplasmic domains of the granulocyte colony-stimulating factor receptors in eight cases of severe congenital neutropenia (Letter to the Editor). Blood 85, 852 .

19. Rauprich P., Kasper B., Tidow N. \& Welte K. (1995) The protein tyrosine kinase JAK2 is activated in neutrophils from patients with severe congenital neutropenia. Blood $86,4500$.

20. Dong F., Van Paassen M., Van Buitenen C., Hoefsloot L. H., Löwenberg B. \& Touw I. P. (1995) A point mutation in the granulocyte colony-stimulating factor receptor (G-CSF-R) gene in a case of acute myeloid leukemia results in the overexpression of a novel G-CSF-R isoform. Blood 85, 902. 